\title{
LEITORES, POR QUE NÃO? A EXPERIÊNCIA LITERÁRIA E A REMIÇÃO DE PENA PELA LEITURA EM PENITENCIÁRIAS FEDERAIS BRASILEIRAS
}

\author{
Maria Luzineide P. da Costa Ribeiro*
}

\begin{abstract}
Resumo: Esse artigo é um recorte da tese ${ }^{1}$ que investigou o projeto Remição pela leitura realizado nas Penitenciárias Federais Brasileiras de Regime Disciplinar Diferenciado (RDD). Em meio a questões estruturais inerentes a esse regime de confinamento, observa-se que a experiência literária desponta com seu viés emancipatório, tornando-se imprescindível à vida desses leitores. Nessa discussão, apresentamos esse espaço de confinamento, suas especificidades e o perfil desse leitor que, de certa maneira, se diferencia dos demais leitores encarcerados no país. Em suma, para além de uma medida redutora de dias, compreendemos que a prática literária reduz os efeitos da prisionização e contribui significativamente para a reformulação da visão de mundo do indivíduo encarcerado.
\end{abstract}

Palavras-chave: Confinamento.RDD.Leitura. Remição de pena.Emancipação.

\begin{abstract}
This article is a cut of the thesis that investigated the project Remição by the reading carried out in the Brazilian Federal Penitentiaries of Differential Disciplinary Regime (RDD). Amid the structural questions inherent in this regime of confinement, it is observed that the literary experience rises with its emancipatory bias, becoming essential to the lives of these readers. In this discussion, we present this space of confinement, its specificities and its profile that, in a certain way, differs from the other imprisoned readers in the country. In short, in addition to a reductive measure of days, we understand that literary practice reduces the effects of imprisonment and contributes significantly to the reformulation of the incarcerated individual's world view.
\end{abstract}

Keywords: Confinamento.RDD.Reading. Remission of penalty. Emancipation.

\section{Introdução}

Quem dormiu no chão deve lembrar-se disso, impor-se disciplina, sentar-se em cadeiras duras, escrever em tábuas estreitas. Escreverá talvez asperezas, mas é delas que a vida é feita: inútil negá-las, contorná-las, envolvê-las em gaze. (Graciliano Ramos)

Com mais de 700.000 pessoas presas, não há como negar que o hiperencarceramento foi adotado pela política prisional brasileira como a principal arma de combate ao crime. Com isso, vimos, há décadas, o fenômeno da superlotação avançar sobre uma população carcerária pobre, negra e com baixo grau de instrução: um retrato perverso da miséria brasileira e da ausência de direitos humanos fundamentais (BRASIL, 2017).

Em meio a esse cenário de superlotação e de ausência de políticas públicas efetivas e eficientes, foram pensadas medidas redutoras de tensão e que não

\footnotetext{
* Doutora em Literatura pela Universidade de Brasília (UnB). Professora da Secretaria de Estado de Educação do DF, atuando na Coordenação de Políticas Educacionais para Juventude e Adultos. E-mail: marialuzineide@gmail.com

${ }^{1}$ Tese defendida no Departamento de Teoria Literária e Literaturas da Universidade de Brasília sob o título: Uma teia de relações: o livro, a leitura e a prisão: um estudo sobre a remição de pena pela leitura em penitenciárias federais brasileiras. 2017.
} 
comprometessem a política interna de segurança das prisões brasileiras. Neste contexto, o livro surge, estrategicamente, como ferramenta de entretenimento para "destensionar" o ambiente e "acalmar" os leitores encarcerados. Com uma realidade prisional de muitas horas de efetivo ócio em cela e poucas horas de banho de sol, a prática literária foi admitida como uma das poucas alternativas de baixo risco à segurança. Em razão disso, a leitura se desenvolveu, largamente, nas prisões brasileiras e o projeto pioneiro federal de Remição de pena pela Leitura deu corpo a essa atividade como uma possibilidade concreta de política pública que, aos poucos, se estendeu às unidades estaduais e, em alguma medida, trouxe consigo a sua legitimidade.

Nessa perspectiva, o indivíduo em restrição de liberdade não pode ser tratado como apenas mais um leitor. Nele, reverbera a ideia de um "leitor real" que tem seu mundo afetado pela complexidade do confinamento, tendo em vista sua rígida estrutura de monitoramento e excessiva preocupação com a segurança que interferem, sobremaneira, na sua rotina e, indiscutivelmente, na sua prática literária. (TINOCO, 2010). Considerando as práticas de leitura, suas relações estéticas e implicações legais nas Penitenciárias Federais Brasileiras, entende-se a Leitura como espaço de liberdade no processo perverso de confinamento. (RIBEIRO, 2017).

Muito se discute o preso, a prisão, mas pouco se fala sobre sua prática literária, como se não fosse dado a eles esse direito, o que sem dúvida, levantaria algumas questões e que aqui poderiam ser analisadas, dando maior visibilidade a este leitor: Como funciona a Remição de pena pela leitura? Quem são esses leitores? Qual a frequência e recepção dessa leitura? Qual a sua representação neste ambiente?

Por isso, é imperioso voltar o olhar para essa microssociedade que, embora formada por menos de $1 \%$ da população prisional, exerce forte influência sobre o Sistema penal brasileiro, justamente, por representarem as lideranças de facções criminosas. Em igual medida, observa-se que tais sujeitos também são leitores em potencial, dado o alto grau de confinamento. (RIBEIRO, 2017). Desse modo, a proposta desse estudo é dizer dessa realidade e de suas especificidades, sob a ótica deste leitor, a partir de suas experiências literárias na prisão, sobretudo diante do Projeto Remição pela Leitura.

Assim, esse estudo foi subdividido em seções que tratam da perspectiva do encarceramento brasileiro e das razões que, em linhas gerais, consolidaram a remição de pena pela leitura como política pública; do Sistema Público Federal (SPF) e da descrição do projeto Remição pela Leitura. De outro lado, tratamos do perfil do leitor e das suas relações com o leitor, a partir do instrumental elaborado por teóricos da Estética da Recepção e da Sociologia da Leitura (ISER, JAUSS, SARTRE e JOUVE). Assim, consubstanciados em relatos de internos, delineia-se a prática de leitura e sua representação. Por fim, as considerações finais arrematam esse artigo.

\section{Por dentro do "Cadeião": conhecendo o Projeto Remição pela Leitura}

Em função do encarceramento massivo e da forte atuação das facções no interior dos presídios brasileiros, o Departamento Penitenciário Nacional (DEPEN) pensou em novas estratégias para manutenção de sua ordem interna ${ }^{2}$. Assim, o Estado assumiu uma

\footnotetext{
${ }^{2}$ Segundo o Manual de Tratamento Penitenciário integrado para o Sistema Penitenciário Federal (2011), para a criação do SPF em 2006, foi necessária uma reestruturação do DEPEN/MJ, que ficou encarregado de administrá-lo. Até então, o DEPEN/MJ não administrava instituições prisionais, mas tão somente coordenava as políticas públicas do Sistema Penitenciário Nacional, bem como era responsável pelo repasse e fiscalização de verbas para os estados. Apesar de suas peculiaridades, o Sistema Penitenciário Federal obedece, inicialmente, ao mesmo regime jurídico geral de todo o Sistema Penitenciário Nacional:
} 
política de austeridade e de extremo controle, com a criação de espaços disciplinares, especialmente pensados para conter líderes e grupos organizados. Com isso,

em dezembro de 2003, a Lei n.10.792 passou a regulamentar o chamado Regime Disciplinar Diferenciado (RDD). Por essa lei, presos que provoquem rebeliões e atos de indisciplina podem ser mantidos até 360 dias em presídios ou alas especiais de presídios, confinados 22 horas por dia em celas individuais, sem realização de atividades e com rigorosa restrição de visitas. Assim, em algumas unidades prevalece, pelo menos aparentemente, o controle sobre os presos, a disciplina, a imobilização, o bloqueio das comunicações com o mundo exterior. (ADORNO e SALLA, 2007).

As Penitenciárias Federais Brasileiras são, sem sombra de dúvida, um território particular dentro do universo caótico das prisões brasileiras. Com celas individuais, sem problemas de superlotação e um eficiente sistema de segurança ${ }^{3}$, estes espaços seriam adequados ao cumprimento da Lei de Execução Penal, não fossem suas limitações para execução efetiva de políticas públicas de ressocialização.

As Penitenciárias Federais têm por objetivo retirar os "líderes de organizações criminosas" de suas prisões locais para que não haja um total estrangulamento do Sistema Penitenciário, conhecido, amplamente, no cenário nacional, como "escritório" da gestão criminal que promove fugas, crimes violentos, entre outras ações que geram a desordem. Com pequenos exércitos arregimentados no interior das prisões, o crime se organiza, inclusive, nestes espaços. Daí a proposta do Regime Disciplinar Diferenciado (RDD), com fulcro na neutralização e afastamento de tais indivíduos, por tempo determinado ou, em alguns casos, indeterminado. Nestes ambientes, a principal preocupação é a contenção e o monitoramento do criminoso. ${ }^{4}$

Atualmente, o Sistema Público Federal (SPF) conta com quatro penitenciárias federais: Penitenciária Federal de Catanduvas (PFCAT), Penitenciária Federal de Campo/MS (PFCG), Penitenciária Federal de Porto Velho/ RO (PFPV). Como penitenciárias de segurança máxima, tem um padrão arquitetônico comum: possuem 208 celas individuais e 12 de isolamento, tendo sua área construída 12.700 metros quadrados. Ainda, em construção, encontra-se a $5^{\text {a }}$ Penitenciária Federal, localizada em Brasília/DF, com previsão de inauguração para este ano.

A Penitenciária Federal de Catanduvas (PFCAT) foi pioneira no desenvolvimento do projeto de Remição pela leitura, considerado projeto piloto e iniciado em julho de 2009. Destacou-se entre as penitenciárias federais por maior regularidade no seu funcionamento, mesmo com intervalo de paralisação de suas

as Regras Mínimas das Nações Unidas para o Tratamento de Reclusos, a Constituição Federal de 1988 e a Lei de Execução Penal (Lei no 7.210, de 11 de julho de 1984).

\footnotetext{
${ }^{3}$ Monitoramento 24 horas por cerca de 200 câmeras de vídeo. Parte delas está instalada em locais sigilosos. Elas enviam imagens em tempo real para três centrais de monitoramento - no próprio prédio, na superintendência da Polícia Federal de Campo Grande e na central de inteligência penitenciária do DEPEN, em Brasília. Advogados, visitantes e funcionários são submetidos a procedimentos de segurança antes de entrar na unidade. Os advogados não tem contato físico com os detentos e conversam apenas por interfone. As visitas são vigiadas por câmeras. Todo o agente penitenciário federal tem suas conversas com os presos gravadas por microfones de lapela, equipamento de uso obrigatório.

${ }^{4}$ O Depen é responsável pelo Sistema Penitenciário Federal, cujos principais objetivos são isolamento das lideranças do crime organizado, cumprimento rigoroso da Lei de Execução Penal e custódia de: presos condenados e provisórios sujeitos ao regime disciplinar diferenciado; líderes de organizações criminosas; presos responsáveis pela prática reiterada de crimes violentos; presos responsáveis por ato de fuga ou grave indisciplina no sistema prisional de origem; presos de alta periculosidade e que possam comprometer a ordem e segurança pública; réus colaboradores presos ou delatores premiados.
} 
atividades em torno de dois anos, mantendo a estabilidade em número e tempo destinado às atividades de leitura. Popularmente conhecida em Catanduva por "Cadeião", a penitenciária Federal de Catanduva (PFCAT) localiza-se a 476 quilômetros de Curitiba, na região oeste do Paraná. Foi a primeira penitenciária federal de segurança máxima a ser inaugurada no Brasil, em maio de 2006. Logo após a sua inauguração, recebeu criminosos conhecidos como Luís Fernando da Costa, vulgarmente conhecido como Fernandinho Beira-Mar, preso há 11 anos neste regime, além de alguns traficantes importantes na cena carioca.

A segunda unidade inaugurada foi a Penitenciária Federal de Campo/MS (PFCG) em dezembro de 2006, localizada na zona rural. Esta unidade também segue o mesmo padrão arquitetônico das demais unidades federais e abrigou chefes do tráfico internacional, nacional e bicheiros cariocas. A adesão ao projeto de remição na PFCG se deu em 2010 e foi duramente atingida pelo intervalo de quase 4,5 anos na paralização de suas atividades.

Em maio de 2008, foi inaugurada a Penitenciária Federal de Porto Velho/ RO (PFPV), terceira Penitenciária Federal de segurança máxima, em função de rebeliões constantes na Penitenciária Estadual de Urso Branco em Roraima. Metade dos presos desta unidade é oriundo do próprio estado. Por isso, apresenta um índice maior de visitas sociais da família. O projeto de remição pela leitura nesta unidade foi iniciado em 2012. Foi a segunda maior em adesão com regularidade em número de participantes. Nessa unidade, os índices de aprovação foram altos, entre 80 e $90 \%$, sendo pontuais os casos de discrepância entre resenhas produzidas e aprovadas. A PFPV demonstrou maior aproveitamento e regularidade na produção de suas resenhas, em cerca de $90 \%$.

A última Penitenciária Federal inaugurada, em julho de 2009, foi a unidade de Mossoró, localizada no estado do Rio Grande do Norte. Assim, como as demais unidades, conta com celas de $7 \mathrm{~m}^{2}$ e 17 portões que as separam do seu portão de entrada. Em 2012, iniciou-se o projeto de remição da leitura nesta unidade. A PFMOS foi a unidade onde se concentrou o maior índice de aprovação, em torno de 90 a 100\% nos anos de funcionamento do projeto. Foram pontuais os casos em que o texto resenhado não apresentou condições de ser aprovado. Em termos de intervalo nas atividades, mesmo com um número menor de participantes, a PFMOS apresentou uma regularidade em sua participação.

Segundo a Coordenação Geral do Tratamento Penitenciário (CGTP), órgão responsável pela gestão das políticas públicas voltadas para o Sistema Penitenciário Federal, o projeto de remição pela leitura iniciou-se em 2009 e foi considerado exequível em virtude do baixo custo, além de conferir a conotação de formação intelectual e de produção, condições que validam a solicitação de remição dos dias. $\mathrm{O}$ projeto, segundo a CGTP, tem uma boa recepção, estimulando a escrita dos presos leitores.

Tal projeto não é obrigatório nas penitenciárias federais, atende, a priori, ao direito do preso a atividades educacionais complementares, conforme, determina a Portaria 276/2012 do Departamento Penitenciário Nacional (DEPEN). Com isso, é disponibilizada uma obra literária, clássica, científica ou filosófica para que num prazo de 21 a 30 dias, após a sua leitura, o preso produza uma resenha a respeito do assunto, possibilitando a remição de 04 dias de sua pena e, ao final, de 12 obras lidas e avaliadas, esse terá a possibilidade de remir 48 dias no prazo de 12 meses de sua pena.

Fig. 1- Execução do projeto de leitura como remição de pena nas penitenciárias federais brasileiras 


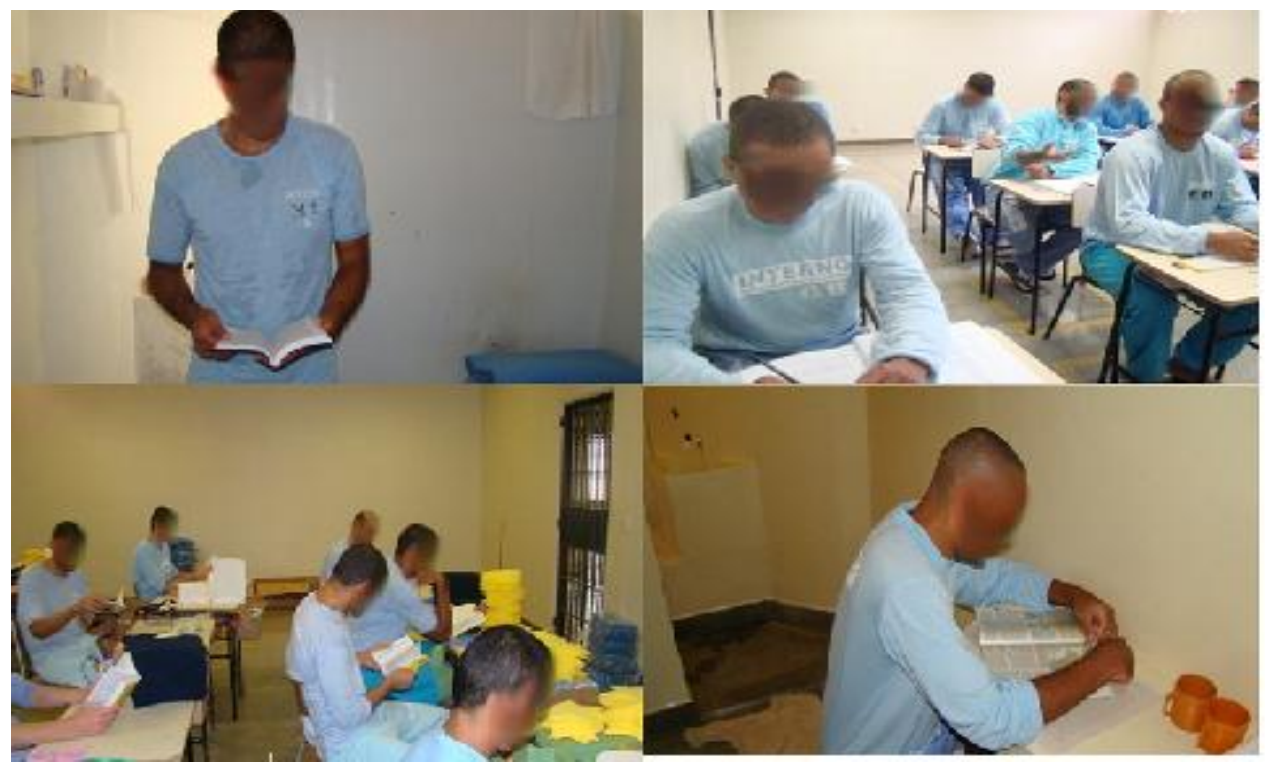

Fonte: DEPEN/MJ

Segundo Ribeiro (2017), entre 2009 a 2016, o projeto apresentou a adesão de $60 \%$ dos presos, sendo produzidas durante este período 7179 resenhas. Além disso, esse modelo de projeto foi replicado por várias unidades da federação. A biblioteca é um espaço comum em todas as penitenciárias federais, contudo os presos não têm acesso livre. Logo, o projeto se dá prioritariamente em cela. O acervo é composto por livros, revistas e obras literárias, censurados os títulos que firam a moral e os bons costumes, com temática voltada para a violência e para o crime ou que coloquem em risco a segurança institucional. O preso pode ter consigo até 05 (cinco) livros, revistas, gibis ou passatempos, conforme sua capacidade de leitura, devendo esses ser substituídos semanalmente. (BRASIL, 2015).

\section{Entre "ladrões e traficantes", o leitor}

Para além da figura do criminoso, neste estudo o nosso olhar se volta para o leitor, produto de relações pouco conhecidas, socialmente, mas que também são estabelecidas no interior da prisão e que, em certa medida, apontaram para a necessidade de se pensar políticas públicas de estímulo à leitura para esse público leitor.

Os indicadores aqui trabalhados foram levantados a partir do I Anuário do DEPEN/MJ que contou com a adesão espontânea de 367 internos do SPF, levando-se em consideração que, à época, essa população contava com 430 internos. Deste modo, foram respondidos $85,35 \%$ dos questionários. A participação na pesquisa se deu de forma voluntária, sendo assegurado ao interno o anonimato. (BRASIL, 2015).

Os dados examinados foram divididos em dois grupos de informações. Em primeiro plano, será descrito o perfil socioeconômico do apenado, desde a sua faixa etária, raça, estado civil. Em seguida, sob a ótica do apenado uma avaliação do SPF, no que tange a seus aspectos negativos e positivos. Em algumas análises, que julgamos pertinentes (faixa etária, raça, estado civil), comparamos o Sistema Penitenciário Federal (SPF) e o Sistema Penitenciário Nacional, que aqui será chamado de Sistema Prisional Comum (SPC).

Considerando a faixa etária, no SPF observamos uma população mais velha, com idade média mais elevada, em que $41,34 \%$ dos presos têm entre 35 e 45 anos fase considerada de maior maturidade. Por sua vez, no SPC, vimos uma população em 
idade produtiva, com uma porcentagem de jovens (18 a 29 anos) bem maior, em torno de 56\%. Ainda se percebeu no SPF, a presença de pessoas mais velhas, entre 46 e 60 anos $(12,01 \%)$, número superior aos $7 \%$ representantes desta faixa etária no SPC. (Cf. tabela 1, abaixo).

Tab. 1-Faixa etária dos presos do Sistema Prisional Comum e do Sistema Penitenciário Federal (em percentagem)

\begin{tabular}{lcc}
\multicolumn{1}{c}{ Faixa etária } & SPF & SPC \\
\hline Acima de 61 anos & 0,56 & 1 \\
46 a 60 anos & 12,01 & 7 \\
35 a 45 anos & 41,34 & 17 \\
30 a 34 anos & 26,54 & 19 \\
25 a 29 anos & 14,80 & 25 \\
18 a 24 anos & 4,75 & 31 \\
\hline
\end{tabular}

Fonte: DEPEN/MJ (2015)

Quanto à raça, a cor ou a etnia, tanto no SPF como no SPC, não foram percebidas muitas diferenças, já que apresenta um traço, infelizmente, comum a toda população carcerária brasileira. Enquanto no SPF, a proporção de negros é de $63 \%$, no SPC, essa proporção cresce e alcança 67\%. Por sua vez, a raça branca representa, aproximadamente, $35 \%$ no SPF, bem próxima dos $31 \%$ do SPC. Não se evidencia, portanto, nesta análise um quadro muito diferente entre os dois recortes analisados. (Cf. tabela 2, abaixo).

Tab. 2- Raça, cor ou etnia dos presos do Sistema Prisional Comum e Sistema Penitenciário Federal

\begin{tabular}{lcc}
\multicolumn{1}{c}{ Raça, cor ou etnia } & SPF & Sistema Prisional Comum \\
\hline Branca & 35,69 & 31 \\
Negra (pardos e pretos) & 60,62 & 67 \\
Indígena & 2,15 & 1 \\
Amarela & 1,54 & 1 \\
\hline
\end{tabular}

Fonte: DEPEN/MJ (2015)

Em relação ao estado civil, o perfil dos presos do SPF é muito diferente das unidades do SPC. Os presos das unidades federais estão, em sua maioria, em situação de união estável $(54,8 \%)$, apenas $22,91 \%$ se dizem casados e apenas $18 \%$ assumiram a condição de solteiros. Em contrapartida, no SPC, a maioria dos presos é solteira (57\%). Apenas $10 \%$ são casados. Em união estável, este número representa 29\%. (Cf. tabela 3 ,abaixo).

Tab. 3-Estado Civil dos presos no Sistema Prisional Comum e no Sistema Penitenciário Federal 


\begin{tabular}{lcc}
\hline União Estável & 54,80 & 29 \\
Casado & 22,91 & 10 \\
Solteiro & 18,27 & 57 \\
Separado & 3,10 & 1 \\
Divorciado & 0 & 1 \\
\hline
\end{tabular}

Com fulcro na formação deste leitor e trajetória educacional, foi feito um recorte dos dados estatísticos cedidos pelo SPF, presentes no I anuário de 2015, que permitiu verificar alguns aspectos da vida destes leitores, relacionados ao nível de instrução, as razões que levaram ao abandono escolar, as atividades profissionais antes da prisão, bem como as razões para não continuarem os estudos na prisão, a capacidade de leitura e escrita destes sujeitos e, por fim o hábito e frequência de leitura na prisão.

Iniciando a segunda fase da análise, apresentaremos os dados referentes à escolaridade. Os indicadores demonstram que a maioria dos presos do SPF tem ensino fundamental incompleto $(38,13 \%)$, mas ainda em percentagem menor do que o registrado SPC (53\%). Por outro lado, percebeu-se uma proporção maior de presos com ensino médio completo (21\%), ou superior (2,5\%) no SPF do que se tem informação no SPC, assim se observa no ensino médio incompleto (11\%), e respectivamente, no ensino superior (1\%). Todavia, ainda observou-se a presença de analfabetos $(2,81 \%)$ no SPF, mesmo que considerada três vezes menor do que no SPC $(6 \%)$. (Cf. tabela 4 , abaixo).

Tab. 4-Escolaridade no Sistema Prisional Comum e Sistema Penitenciário Federal (em percentagem)

\begin{tabular}{lrc}
\multicolumn{1}{c}{ Escolaridade } & SPF & Sistema Prisional Comum \\
\hline Superior Completo & 2,5 & 1 \\
Ensino superior Incompleto & 3,13 & 1 \\
Ensino Médio Completo & 9,38 & 7 \\
Ensino Médio Incompleto & 21,88 & 11 \\
Ensino Fundamental completo & 10 & 12 \\
Ensino fundamental incompleto & 38,13 & 53 \\
Alfabetizado & 12,19 & 9 \\
Analfabeto & 2,81 & 6 \\
\hline
\end{tabular}

Fonte: DEPEN/MJ -2015

Quando analisados os dados sobre as razões que levaram ao abandono dos estudos, $60,48 \%$ indicaram a necessidade de trabalhar, $24,05 \%$ indicaram fatos relacionados à prática criminosa, apenas $11,68 \%$ admitiram estar desinteressados pelos estudos. Ainda com relação a este tópico, 74,42\% afirmam não estudar há mais de 10 anos, já para 13,95\% este tempo sem estudar representa entre 06 e 10 anos. Apenas $11,63 \%$, estão sem estudar pelo menos há 5 anos.

Tab. 5- Razão para o abandono dos estudos (em percentagem)

Razão para o abandono dos estudos 


\begin{tabular}{ll}
\hline Necessidade de trabalhar & $60,48 \%$ \\
$\begin{array}{l}\text { Fatos relacionados à prática } \\
\text { criminosa }\end{array}$ & $24,05 \%$ \\
Desinteresse pelos estudos & $11,68 \%$ \\
\hline
\end{tabular}

Fonte: DEPEN/MJ -2015

A ausência de oportunidade é a principal razão para não estudar, o que equivale dizer que $69,57 \%$ fizeram tal afirmativa no SPC, e este número aumentou para $\mathbf{7 8 , 9 2 \%}$ no SPF. De toda sorte, verificou-se que o percentual relacionado à falta de oportunidade como principal razão a não realização de atividades educacionais no interior das prisões representa $70 \%$ a $80 \%$ da massa carcerária de ambos os sistemas.

Tab. 6- Razão para o não acesso à educação formal no SPF (em percentagem)

\begin{tabular}{lcc}
\multicolumn{1}{c}{ Razão } & SPF & Sistema Prisional Comum \\
\hline Já concluí os estudos & 5,95 & 6,83 \\
Não tive interesse & 15,14 & 23,6 \\
Falta de oportunidade & 78,92 & 69,57 \\
\hline
\end{tabular}

Fonte: DEPEN/MJ -2015

Quando o foco recai sobre a capacidade de escrita dos presos do SPF, verificamos que a autoimagem destes sujeitos é, na sua maioria, positiva, pois para 49,23\%, sua capacidade de escrita pode ser considerada boa ou ótima. Apenas $38,7 \%$ consideram sua capacidade de escrever regular e um pouco mais de $12 \%$ admitem ser péssima ou ruim.(Cf. tabela 7, abaixo).

Por sua vez, quando interrogados sobre a sua capacidade de leitura, os presos do SPF, são ainda mais otimistas, pois um pouco mais do que $70 \%$ avaliam-na como boa ou ótima. Para $23,15 \%$, a capacidade de leitura pode ser considerada regular e apenas $6,47 \%$ consideram que sua capacidade de leitura esteja comprometida por ser avaliada como péssima ou ruim. (Cf. tabela 8, abaixo).

Levando-se em consideração a boa condição de leitura avaliada pelos próprios presos, quando interrogados sobre o Hábito de leitura, verificou-se que apenas 3,74\% admitiram não costumam ler, reverberando na maioria das respostas de cerca de $\mathbf{6 0 \%}$ que já tinham a leitura como prática, e 36, 76\% afirmaram que o ato de ler se deu somente após sua entrada no SPF.

Tab. 7-Capacidade de leitura e escrita dos presos do Sistema Penitenciário Federal (em percentagem)

\begin{tabular}{lcc}
\hline & Capacidade de leitura & Capacidade de escrita \\
\hline Ótima & 26,23 & 10,53 \\
Boa & 44,14 & 38,70 \\
Regular & 23,15 & 38,70 \\
Péssima & 5,85 & 3,41 \\
Ruim & 0,62 & 8,67 \\
\hline
\end{tabular}

Fonte: DEPEN/MJ -2015

Outro dado importante diz respeito ao hábito da leitura, que independente da participação no projeto de Remição pela Leitura, faz parte da rotina carcerária de $\mathbf{9 6 \%}$ dos presos no SPF. Alinhada a esta perspectiva, está a frequência de leitura que neste aspecto alcança $\mathbf{8 0 , 9 1 \%}$ desses presos que leem mais de $\mathbf{1 0}$ livros por ano, enquanto 
$(7,12 \%)$ afirma ler 10 livros por ano; $6,15 \%$ leem 05 livros por ano e apenas 3,88\% leem 01 livro ao ano. Consideram-se não leitores apenas 1,94\%.(Cf. tabela 8, abaixo).

Tab. 8 - Hábito de leitura no Sistema Penitenciário Federal (em percentagem)

Hábito de leitura no SPF

\begin{tabular}{lc}
\hline Leio mais de 10 livros por ano & 80,91 \\
Leio 10 livros por ano & 7,12 \\
Leio 5 livros por ano & 6,15 \\
Leio 1 livro por ano & 3,88 \\
Não leio & 1,94 \\
\hline
\end{tabular}

Fonte: DEPEN/MJ -2015

É importante mencionar que na $4^{\mathrm{a}}$ edição da pesquisa Retratos da leitura no Brasil realizada entre os meses de novembro e dezembro de 2105 , foram entrevistadas 5012 pessoas e as principais razões apontadas para não praticarem a leitura foram a ausência de tempo, a própria dificuldade para ler e a falta de paciência. Neste sentido, aos presos do SPF, sobram "tempo e paciência para a leitura".

Quando perguntados sobre o sistema prisional no qual se encontram, os internos fazem sua avaliação pessoal. Seguindo a descrição apontada no I anuário, alguns aspectos elencados foram indicados como pontos negativos e outros como pontos positivos dentro de suas unidades (Cf. gráfico 1, abaixo). Como principal ponto negativo, a alimentação foi mais indicada por $17,64 \%$. Em seguida, o respeito aos direitos dos presos foi apresentado como mais um aspecto fragilizado dentro desta realidade para $13,66 \%$. Outro aspecto que chama atenção para $13,18 \%$, como ponto negativo, é a assistência médica. Para $12 \%$, outro problema é a assistência, de forma geral, aos internos.

$O$ tratamento dispensado aos internos e o tratamento dado pelos servidores alcançam juntos aproximadamente $26 \%$ da insatisfação dos internos. A cela individual foi apontada em sétima posição para $10,56 \%$ como aspecto negativo. Voltando à assistência à saúde, o setor mais fragilizado foi a assistência odontológica. Ao final, os internos apontaram a limpeza $(6,59 \%)$ e a biblioteca $(4,36 \%)$ como pontos a serem melhorados. Quando comparamos os dados relacionados aos aspectos negativos e aos positivos, percebe-se coerência na avaliação dos internos. (Cf. Gráfico 1, abaixo).

Gráf. 1- Pontos negativos no SPF - opinião dos internos 


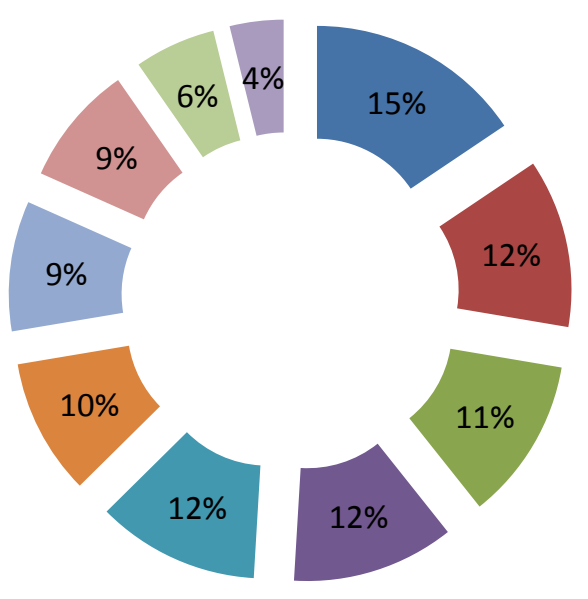
- Alimentação
- Respeito aos direitos dos
presos
- Assistência médica
- Assistência aos internos
- Tratamento aos internos
- Tratamento dos servidores
- Cela individual
- Assistência odontológica
Limpeza
Biblioteca

Fonte: DEPEN/MJ -2015

Gráf. 2- Pontos positivos no SPF- opinião dos internos

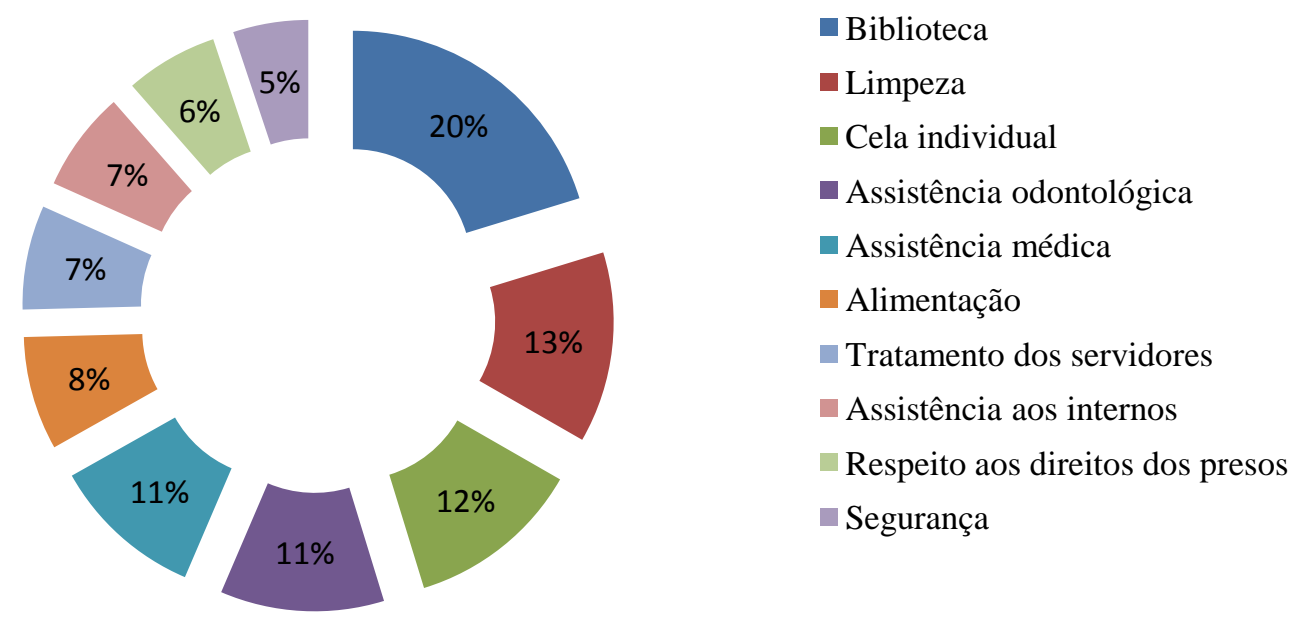

Fonte: DEPEN/MJ -2015

Curiosamente, a biblioteca surge, no topo da análise, com o primeiro ponto positivo para $20,26 \%$ dos entrevistados, embora não façam uso do espaço, reforçam a tese da importância do livro neste ambiente. Em seguida, surge a limpeza que para 13\% dos entrevistados é outro aspecto muito positivo. A cela individual surge na terceira posição com aproximadamente $12 \%$ das respostas. A assistência médica e odontológica representa a marca de $22 \%$ de satisfação dos internos. A alimentação ainda é classificada como ponto positivo para $7,75 \%$ dos entrevistados, seguida do tratamento dos servidores $(7,11 \%)$. Neste aspecto, a assistência aos internos aparece logo depois para $6,84 \%$. Em penúltima posição, temos o respeito aos direitos dos presos com 6,32\% de classificação positiva e, por último, o aspecto segurança com 5,13\%. (Cf. Gráfico 2, acima). 


\section{Nas franjas do imaginário: a liberdade}

Quando pensamos na prática da leitura, aproximamo-nos imediatamente do seu caráter subjetivo e nos interrogamos: "O que acontece quando lemos um livro? Quais as sensações, as impressões que a leitura suscita em nós?" Em resposta a estas perguntas, duas perspectivas avizinham-se: enquanto Jauss (1979) afirma que o texto permite a "fruição estética" - uma experiência particular -, Barthes (1980) a descreve como um colocar-se em estado de perda, de desconforto, abalando convicções históricas, psicológicas e de valores. Nesta mesma linha de argumentação, o escritor francês ainda nos diz que o leitor se coloca em crise, e nesta condição, é libertado pelo imaginário de tudo aquilo que o prende a uma realidade de vida, muitas vezes, constrangedora.

Nesta mesma direção, Sartre (1996), em sua obra $O$ imaginário, mostra que a consciência "imaginante", de fato, conduz o leitor a uma sensação dupla de liberdade e de criatividade. Contudo, para que isso ocorra, é necessária a "aniquilação" do mundo do sujeito, e, por conseguinte, a criação de um mundo novo em substituição ao primeiro.

Dessa forma, percebemos as ideias de Jauss bem alinhadas à proposta de Sartre, no momento em que o estudioso alemão afirma que a leitura, como experiência estética, resulta sempre "tanto libertação de alguma coisa, quanto libertação para alguma coisa". Se por um lado, a leitura permite ao leitor desprender-se das incongruências de uma vida real; por outro, ao se deslocar para o universo textual, o leitor renova sua percepção do mundo. E nesse novo contexto, o leitor tem a impressão de escapar de si próprio, ao mesmo tempo, em que se abre também para uma experiência de alteridade.

Ler, portanto, torna-se uma viagem. Percebemos a confluência destas ideias, na obra A leitura de Vincent Jouve (2002, p.108), quando o autor, ao sintetizar o ato da leitura, o compreende como uma entrada insólita em outra dimensão que, na maioria das vezes, enriquece a experiência, e permite ao leitor, num primeiro momento, escapar desta realidade para o universo da ficção, e num segundo momento, de maneira ainda mais surpreendente, voltar ao real, nutrido do que chama de fictício. É neste vaivém que o autor esclarece a questão:

Ao ler um romance, aceitamos esquecer por um tempo a realidade que nos cerca para nos ligarmos novamente com a vida da infância na qual histórias e lendas eram tão presentes. Ao acordar o eu imaginário, normalmente adormecido no adulto acordado, a leitura nos leva de volta ao passado. (JOUVE, 2002, p.115).

Percebemos, assim, que o imaginário de cada leitor tem um papel tal na representação que poderíamos quase falar de uma "presença" da personagem no interior deste leitor. E essa sensação de consubstancialidade entre o sujeito que lê e a personagem representada, não poderia jamais ser dada sob nenhuma ótica, se não esta agora citada. Pensando, então, na força de toda esta energia psíquica, Jouve (2002) afirma que o leitor, neste processo, assemelha-se a um sonhador. E quando pensamos, então, a leitura, a partir de uma dimensão onírica, vimos que, a princípio, ela é fundamentada numa imobilidade relativa, uma espécie de vigilância restrita (inexistente para aquele que dorme) e, posteriormente, ocorre uma suspensão da postura ativa em favor de uma mais receptiva.

De fato, a liberdade pela fruição literária abriu uma nova dimensão ao leitor - o imaginário - a partir desta condição, todo o processo subjetivo desaguou nas emoções, nas relações de afetividade proporcionada pelo texto. Tal dimensão é potencializada 
pelo confinamento, seja como uma viagem ou mesmo um sonho, é certo que é uma porta que se abre para a liberdade, um escapar-se de si próprio, capaz de ressignificar a vida na prisão e fora dela. Neste sentido, trouxemos à luz dessa discussão alguns trechos de relatos da experiência literária de participantes do projeto Remição pela Leitura no SPF.

Comecemos pelo texto do preso da cela 41 da Penitenciária de Catanduvas (PFCAT), coletado no ano de 2010, nela o preso agradece pela oportunidade de participar do projeto de remição pela leitura. Assim, V.C.S começa o relato (1): "Em se tratando de leitura tudo é genial " e continua reforçando a importância funcional da leitura: "Foi um projeto muito bom, pois mexe com o nosso 'cortex' e com certeza vai en riquecer nossa bagagem de vida, desperta nosso enteresse pela leitura e exercita nossa inteligência"(sic). Dessa forma, V.C.S enfatiza que fica com a "memória mais afiada" e tem muito a ganhar. Em outro trecho destaca que "a leitura por si só já faz um bem tremendo para o ser humano". Mesmo ao final, confessando que tem "pouco estudo e pouco conhecimento da literatura e da leitura", se diz esperançoso com o projeto, pois acredita que "a leitura influi no nosso conhecimento quanto mais ler mais aprendemos (sic)".

Fig. 2 - Relato de participante do Projeto de Remição pela Leitura na PFCAT (Recorte do texto original)

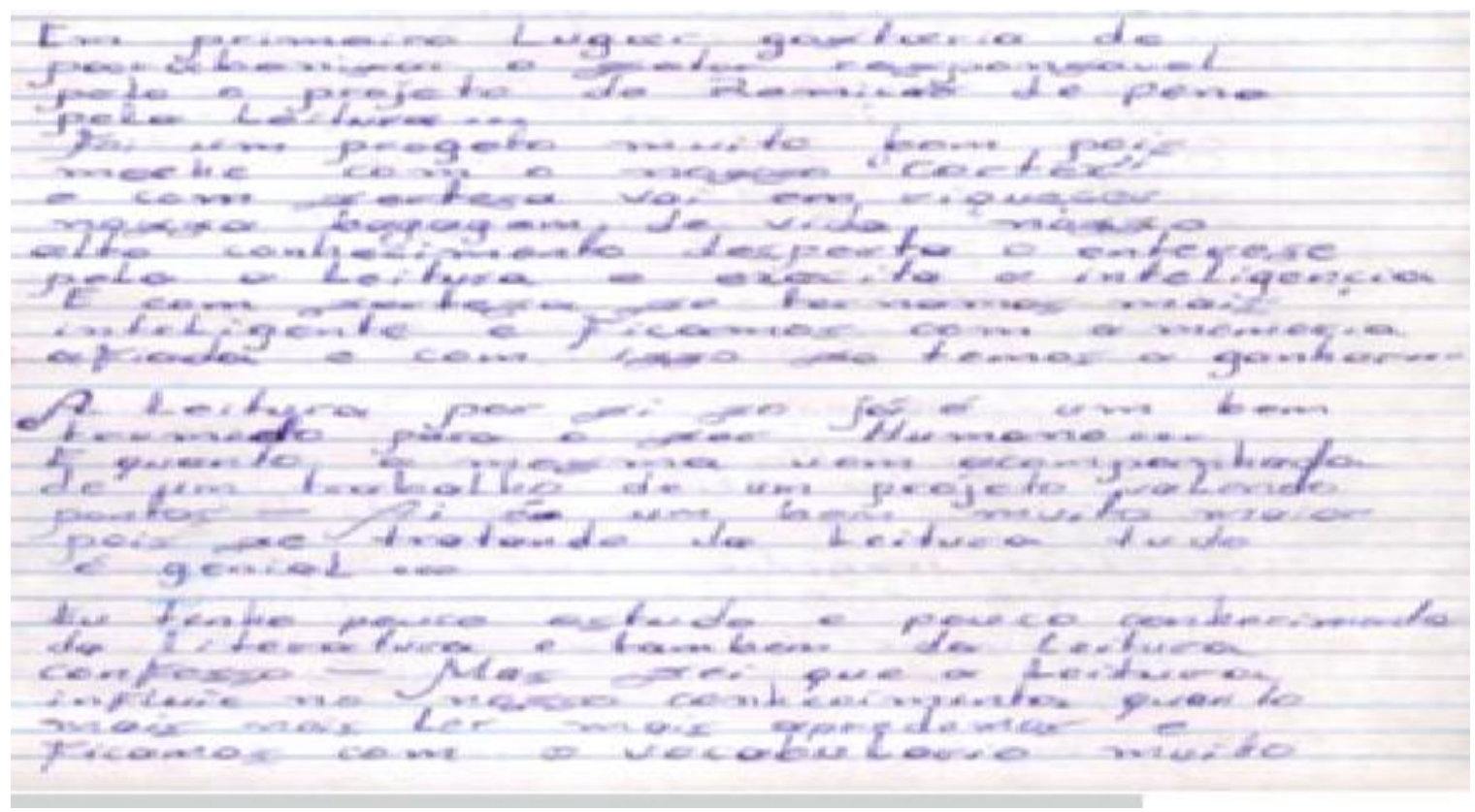

Fonte: DEPEN/MJ

Instigante é o depoimento de M.A.K, preso leitor da Penitenciária Federal de Campo Grande (PFCG) e que no ano de 2012 reiterou a importância da remição de 04 dias pela leitura. Em outras palavras, M.A.K ressaltou que o projeto foi importante também porque o incentivou "a trabalhar seu intelecto de forma mais elaborada, utilizando seu senso crítico e sua imaginação", o que segundo ele, "na rotina diária da penitenciária federal não é muito exercitado". Um ponto que merece destaque neste depoimento é o fato de que para o preso leitor, determinar um prazo significa ter responsabilidade. Descreve tal atitude como compromisso, um aspecto destoante da proposta de toda instituição total de desprogramação da vida do individuo, que segundo Goffman (2001), tem como objetivo a alienação do sujeito para uma melhor modulação de suas vontades. 
Fig. 3- Relato de participante do Projeto de Remição pela Leitura na PFCG (Recorte do texto original)

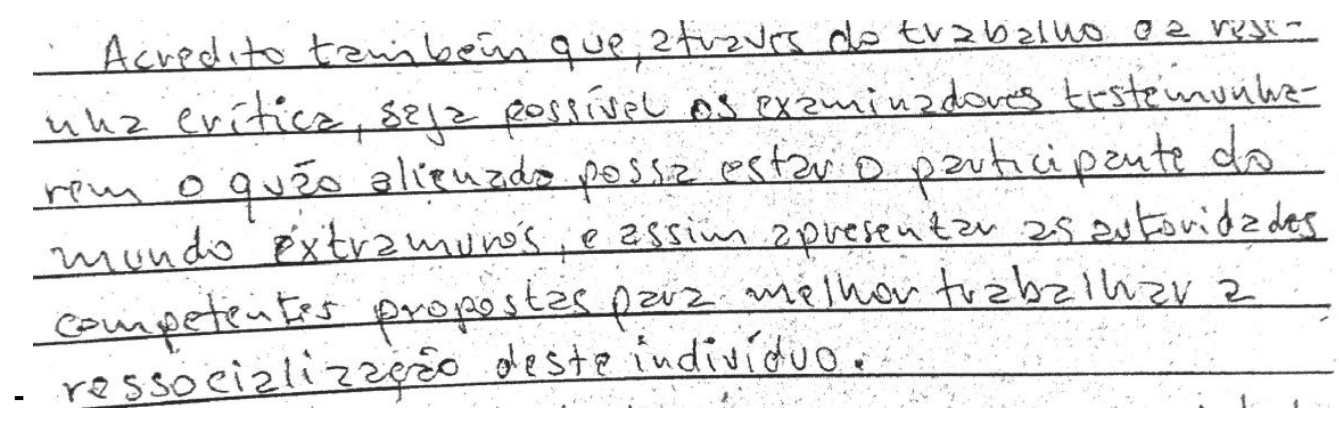

Neste sentido, a ideia de ruptura de rotinas ganha força, sobretudo quando M.A.K, em seu discurso final, lança sua expectativa: "acredito também que, através do trabalho de resenha crítica, seja possível aos examinadores testemunharem o quão alienado possa estar o participante do mundo extramuros, e assim apresentar as autoridades competentes propostas para melhor trabalhar a ressocialização deste indivíduo." Ao final do texto, M.A.K se despede agradecendo por todas as vezes em que pode participar do projeto.

É certo que o ato de leitura na prisão resvala na possibilidade de o leitor atingir o ápice desta leitura, não apenas de informação, mas de intensa relação com o texto, expoente de arte, pura arte. Esta singularidade aproxima o leitor das verdades que o circundam e dos possíveis questionamentos produzidos, a partir desta consciência da verdade. Levando-se em conta, a modulação proposta pelo sistema penal de tornar o corpo do criminoso num corpo dócil, a literatura subverte a ideia de alienação e desprogramação deste sujeito, mesmo que tacitamente.

\section{Considerações finais}

O projeto de Remição pela Leitura nas penitenciárias federais brasileiras reverberou em todo o Brasil com a replicação de programas e com o uso de instrumentos legais que deram sustentação ao seu desenvolvimento, sendo constatada a participação estadual de aproximadamente $30 \%$ em suas unidades prisionais. Mesmo que em números absolutos, a participação dos presos seja pouco expressiva, por representar aproximadamente $1 \%$ da população carcerária, observa-se que o programa foi bem recebido, e que, aos poucos, vem sendo ajustado a cada realidade. (BRASIL, 2017).

No SPF, com "tempo demais e atividade de menos", a leitura representou nas falas dos internos, a possibilidade real de ampliação do conhecimento, de construção do intelecto, além de um exercício de criatividade. Diante disso, é certo que a leitura desautomatiza as relações rotineiras do cárcere, permitindo ao leitor acessar a obra e, ao contextualizá-la, ampliar sua perspectiva de mundo.

Com um maior nível de instrução, os leitores do SPF apresentam números superiores ao Sistema penal comum. Formado por profissionais autônomos e comerciantes, esta população prisional demonstrou interesse em desenvolver alguma atividade laboral e de aperfeiçoamento, como cursos profissionalizantes. Contudo, a ausência de atividades educacionais ou laborais no interior das unidades federais, metade dos presos permanecem ociosos. A inserção no mundo do crime não foi apontada como a principal razão para o abandono dos estudos, mas sim a necessidade de trabalhar. 
Chama atenção o número pequeno de analfabetos e mais ainda o número expressivo de presos que tornam a prática de leitura parte da rotina carcerária. Isso se deve não apenas ao confinamento, mas em virtude dessa prática já fazer parte da rotina extramuros da maioria deles. Por isso, consideram-se melhor ledores do que escreventes. Leem, em média, entre 10 ou mais livros por ano. A leitura no confinamento se revela como artigo de primeira necessidade no cotidiano. No caso do SPF, a leitura se torna elemento vital, pois a ociosidade é potencializada, dado o grau de isolamento do indivíduo (22 horas) em cela individual.

Em meio a um cenário vazio de perspectivas, a prática literária na prisão aventa novas possibilidades, conectando o leitor ao mundo do texto. Assim, o leitor parece permanecer vivo, embora preso a um ambiente extremamente hostil. Desta intersecção entre o mundo da prisão e o mundo do texto, abre-se uma fenda no tempo em que o leitor por um instante parece estar livre para viver outra história.

Dessa forma, é inegável que a experiência literária seja um espaço de liberdade que promove, também, a remição de dias, mesmo quando a rotina prisional impeça o seu impacto, de forma significativa, sobre a vida penal deste indivíduo. O que se revela aqui e colocou-se no cerne do debate foi a prática literária como imprescindível à rotina carcerária à medida que confere a este leitor uma identidade leitora e um sentido de emancipação.

Por fim, acreditamos que iluminar tais realidades e leitores contribui de forte maneira para os estudos literários, dando voz e visibilidade a um público que vive à margem e à sombra da sociedade. Contudo, permaneço consciente de que se trata de uma realidade complexa, que precisa ser problematizada para que seja possível pensar avanços no desenvolvimento de ações de estímulo à leitura nas prisões e, então, efetivamente, quem sabe, possamos ter políticas públicas consistentes voltadas para projetos de leitura em todo o Brasil.

\section{Referências}

ADORNO, Sérgio; SALLA, Fernando. Criminalidade organizada nas prisões e os ataques do PCC. Estudos avançados, v. 21, n. 61, p. 7-29, 2007.

BARTHES, Roland. O rumor da língua. 1980.

BRASIL. Ministério da Justiça, Departamento Penitenciário Nacional, Sistema Penitenciário Federal. Manual do Tratamento Penitenciário integrado para o Sistema Penitenciário Federal, 2011.

BRASIL. Ministério da Justiça, Departamento Penitenciário Nacional, Sistema Penitenciário Federal. Portaria n.276 de 20 de junho de 2012. Dados disponíveis em<http://portal.mj.gov.br/data/Pages/htm>. Acesso em: 27 jan. 2012 >

BRASIL. Ministério da Justiça. Sistema Integrado de Informações penitenciárias do Ministério da Justiça (INFOPEN/MJ). Dados disponíveis em<http://portal.mj.gov.br/data/Pages/htm>. Acesso em: 20 fev. $2017>$

BRASIL. Ministério da Justiça, Departamento Penitenciário Nacional, Sistema Penitenciário Federal. I Anuário do Sistema Penitenciário Federal, 2015. 
GOFFMAN, E. Manicômios, Prisões e Conventos. São Paulo, Editora Perspectiva, 1990.

ISER, Wolfgang. O ato de leitura: uma teoria do efeito estético. São Paulo: Ed. 34, 1996.

JAUSS, Hans Robert. O prazer estético e as experiências fundamentais da poiesis, aisthesis e katharsis. A literatura e o leitor: textos de estética da recepção. Rio de Janeiro: Paz e Terra, v. 16, p. 2-18, 1979.

JAUSS, Hans Robert et al. A história da literatura como provocação à teoria literária. Ed. Ática, 1994.

JOUVE, Vincent. A leitura. São Paulo: Ed. Unesp, 2002

RAMOS, Graciliano. Memórias do cárcere. Rio de Janeiro/São Paulo: Record, 2008.

RIBEIRO, Maria Luzineide P. Uma teia de relações: o livro, a leitura e a prisão: um estudo sobre a remição de pena pela leitura em penitenciárias federais brasileiras. 2017.

SARTRE, Jean Paul. O imaginário. Tradução de Duda Machado. São Paulo: Editora Ática, 1996.

TINOCO, Robson Coelho. Leitor real e teoria da recepção: travessias contemporâneas. Editora Horizonte, 2010.

Recebido em 31 de maio de 2018

Aceito em 23 de julho de 2018 